\title{
La construcción de la identidad nacional patriarcal en Misterio, de Manuel Argüello Mora
}

\author{
Deborah Singer
}

Universidad Nacional, Costa Rica

\section{Resumen}

Se desarrolla la tesis de que esta novela costarricense de finales del siglo XIX configura literariamente la noción de lo costarricense, patrocinada por una ideología patriarcal, de origen oligárquico, de parte de la élite en el poder. Amparada al discurso realista, en la obra se procura dar cuenta de una identidad costarricense. Sobre esto se hace un esbozo teórico a partir de lo cual se ponen en evidencia los procedimientos discursivos del relatode Argüello Mora, para afirmar una patria idealizada o sólo parcialmente histórica.

\section{Abstract}

This article develops the thesis the Costa Rican novel, Misterio, of the late 19th century is a literary configuration of the Costa Rican identity, supported by a patriarchal ideology with oligarchic origins of the elite who are in power. Based on the discourse of realism, the concept of nationality is shown. A theoretical framework is outlined in order to present the narrative techniques used by Argüello Mora, and show how they were used to construct an idealized country which is only partially historical. 
“...quise una vez saber qué tierra era la que le da su nombre a cierta clase de café que se toma en Londres". Manuel Argüello Mora: Misterio'.

El fragmento citado, extraído de la novela que, por muchos, es considerada como precursora de la narrativa costarricense, da cuenta de la importancia de la actividad cafetalera en el desarrollo histórico y social de Costa Rica, pero también (y quizás más importante aun) se enmarca en el momento de la construcción y consolidación de la identidad nacional, es decir, el período comprendido entre el segundo tercio del siglo XIX y las primeras décadas del siglo XX.

Como antecedente, conviene recordar que una vez declarada la emancipación americana, los gobiernos de los jóvenes estados mantuvieron el orden colonial prácticamente intacto, siendo su mayor desafío el logro de una homogeneización de la población que vivía dentro de las fronteras del territorio nacional. Esta (seudo)homogeneización sólo podía llevarse a cabo por medio de la elaboración de un discurso nacional que fuera reconocido por todos como propio, aun si la mayor parte de los habitantes estaba marginada de los asuntos públicos (los campesinos, los indígenas, los negros y las mujeres). Tomando como paradigma el modelo europeo, se hizo uso del aparato educativo, del orden político-jurídico y del discurso de las ciencias sociales como un todo para desarrollar el conjunto de valores que daría cuerpo a una nación única y diferente de todas las demás. En este proceso, la literatura desempeñó un papel fundamental.

Este artículo tiene por objetivo establecer de qué manera la novela Misterio contribuyó a construir simbólicamente la comunidad que conocemos como Costa Rica. A simple vista, Misterio responde a las características propias del estilo folletinesco: la historia de un amor como eje narrativo (que cuando no fructifica culmina con la muerte, el convento o el manicomio), una ambientación centrada en los salones de la clase acomodada, hijos perdidos después del

1. Manuel Argüello Mora, Obras literarias e históricas (San José: Editorial Costa Rica, 1963). 
nacimiento, identidades intercambiadas, secretos de familia y herencias recuperadas. Sin embargo, un análisis más prof undo revela que el argumento se basa en una serie de principios ideológicos que contribuyeron a consolidar la posición hegemónica de la élite políticooligárquica que detentaba el poder y buscaba legitimar un orden patriarcal que favoreciera sus intereses. Para ello, la novela romántica y el discurso amoroso jugaron un valioso papel en la medida en que actuaron como metáfora del proyecto de nación en ciernes, como veremos más adelante.

\section{Antecedentes}

La novela de Manuel Argüello Mora (que muchos llaman protonovela) publicada en 1888, lleva el subtítulo de Escenas de la vida en Costa Rica. A pesar del inicio del texto (“...el día que comienza esta verídica historia"), el mismo Manuel Argüello duda de la veracidad de sus obras, puesto que afirma que sus trabajos "son un refle jo de mi memoria más que un relato histórico", de modo que se produce un juego entre la historicidad y la verosimilitud. Al respecto, el escritor y crítico costarricense Abelardo Bonilla afirma en el prólogo de la edición de 1963, acerca de las obras de Argüello Mora:

Abarca la obra del señor Argüello Mora una de las épocas más inquietantes y menos claras de nuestra historia patria y en ciertos aspectos resulta ya imposible saber hasta dónde llega lo histórico y hasta dónde la fantasía o los intereses del autor².

En Misterio no encontramos alusiones directas a la campaña del 56; sin embargo, existen elementos que nos permiten detectar una propuesta identitaria con características propias. El texto fue publicado durante el período de reformas liberales que consolidaron el Estado

2. Argüello, 14. 
liberal-oligárquico en el país. El Liceo de Costa Rica llevaba un año de fundado y le seguiría el Colegio de Señoritas; estos datos adquieren relevancia si pensamos que se estaba formando una población de lectores potenciales a la cual era preciso "educar" a través de la novela. En el prólogo de la edición del 2004 de Misterio, Juan Durán escribe lo siguiente en relación con el autor: "Su escritura, como buen retrato, debía reflejar el rostro más auténtico de Costa Rica, externo e interno. Aquí yacía el sentido y el fin último de la tendencia realista" ${ }^{3}$.

Argüello se propone retratar la vida costarricense en el más puro estilo del realismo y para darle verosimilitud al texto, emplea el recurso epistolar: no es el narrador quien "habla" sino los mismos personajes que se escriben cartas y en ellas expresan sus emociones en forma directa. Pero el autor tiene además otro objetivo igualmente relevante: llenar el espacio vacío existente en la narrativa nacional como una forma de demostrar que el país se encontraba en el estado de madurez necesario para el desarrollo de las artes y las letras; si el café había puesto a Costa Rica en el mundo, la novela nacional le aseguraría un lugar digno. Pero la publicación de una novela costarricense en aquel entonces significaba muchomásque una oportunidad de esparcimiento para el público lector; estaba en juego la formación de una narrativa que contribuiría a consolidar la identidad de una joven nación.

\section{La construcción de la identidad nacional}

Para esclarecer el papel de la narrativa en la formación de las identidades nacionales conviene hacer un breve paréntesis teórico. En el transcurso de las últimas décadas, se han publicado diversos estudios que tratan el tema específico de las formaciones identitarias. Un gran aporte lo constituyó el libro Imagined Communities ${ }^{4}$, cuyo autor, Benedict Anderson, desarrolla el proceso que dio origen a la

3. Manuel Argüello Mora, Misterio (San José: Editorial de la Universidad de Costa Rica, 2004).

4. Benedict Anderson, Imagined Communities (Nueva York: Verso, 1991). 
formación de los nacionalismos. El fenómeno de la comunidad imaginada se produce desde el momento en que el individuo se siente parte de un conglomerado social con el cual comparte la cultura, aun si sólo conoce a una muy pequeña parte de sus miembros. De esta manera, el sujeto tiene plena certeza de la existencia simultánea y anónima de un grupo humano que puede estar compuesto por millones de personas. La nación no es ilimitada, tiene fronteras específicas y ese aspecto marca su diferenciación de otras naciones que están fuera de los límites reconocidos como propios. Pero la característica más fascinante es quizás la capacidad del conglomerado humano de imaginarse a sí mismo como comunidad hasta el punto en que las desigualdades sociales desaparecen (o son camufladas) por el sentimiento de fraternidad y compañerismo que da la conciencia de pertenecer a un todo orgánico. ¿Cómo se origina y desarrolla esa conciencia? Por medio de una concatenación de aparatos estatales como la educación, los organismos político-jurídicos, la cultura. Pero en los albores de la emancipación, cuando los estados apenas empezaban a levantarse como entes autónomos e independientes, la prensa escrita y la novela cumplieron una importante misión como fundadoras de un espacio propio.

Si recordamos alguna novela recientemente leída, notaremos que hay una constante apelación al lector para que reconozca el paisaje descrito, de modo que se produce una salida del tiempo interior de la novela para acceder al tiempo exterior de la vida diaria. La complicidad que se establece entre el autor y el lector sienta las bases de una sólida comunidad humana, que incluye a diversos autores y lectores moviéndose en una misma dirección a través del tiempo. Por otra parte, la creación de un paisaje sociológico dentro de la novela establece el punto de contacto entre el mundo interior y el mundo exterior. La mera mención de recintos específicos como un monasterio, un cuartel de artillería, un palacio presidencial o una municipalidad, implica que se hace referencia a un espacio claramente delimitado y reconocido por toda la comunidad de lectores. Para reconocer 
una nación, tomamos en cuenta diversos factores que los individuos tienen en común: el idioma, las costumbres, la religión, un pasado compartido, y una formación narrativa que estandariza el lenguaje y da cuerpo a la comunidad imaginada ${ }^{5}$.

La novela y el periódico fueron fundamentales en la definición de límites nacionales. El anuncio de un evento ocurrido en la ciudad o la descripción del paisaje en el cual interactúan los protagonistas de la novela tienen particular trascendencia para la comunidad. La especificación de lugares físicos y de un grupo humano determinado (como la población indígena, los esclavos negros, los sirvientes) favorece un proceso de reconocimiento e identificación por parte del lector, puesto que se trata de eventos ocurridos "aquí" y no en algún lugar lejano del planeta. De hecho, existen formas artísticas específicas que contribuyen enormemente en la estructuración de las nacionalidades - como los poemas patrios, las canciones y los himnos nacionales - lo que demostraría que la nación se concibió desde el principio en la lengua ${ }^{6}$.

La novela extendió y modernizó el imaginario religioso, tocando temas como el origen, la continuidad y la muerte. Además de ello, se ocupa de la realidad diaria elevando a la categoría de "personajes" a sujetos provenientes de los estratos sociales que la élite letrada considera inferiores, haciéndolos parte de la comunidad nacional y otorgándoles un lugar dentro de la pirámide social, se trate o no de un lugar subalterno. Según afirmaba Ernest Gellner: "Nationalism is not the awakening of nations to self consciousness; it invents nations where they do not exist"7.

La descripción de un paisaje urbano propio sienta las bases del espacio nacional. Veamos como lo describe Manuel Argüello Mora.

5. Timothy Brennan, "The National Longing for Form" en Homi Bhabha (comp.), Nation and Narration (Londres: Routledge, 1990).

6. Alicia Poderti, "La nación imaginada. Trayectos ideológicos y ficcionales en el espacio andino" en Anales, Ciudadanía y Nación (Instituto Iberoamericano de la Universidad de Goteborg, 1999).

7. Brennan, op. cit. 


\section{El ambiente en la novela Misterio}

El autor tiene plena conciencia de los estereotipos que circulan en Europa en relación con el paisaje de nuestro continente. El ambiente en Costa Rica, imaginado por la europea Mademoiselle de Roqueval, corısponde plenamente con la visión que se tenía de América desde los tiempos de la conquista. Se sintetiza lo idílico y lo salvaje: ríos caudalosos como no existen en Europa, tempestades que pueden arrasar una ciudad, árboles centenarios, volcanes arrojando fuego, pájaros paradisíacos, y pasiones tórridas, rápidas y destructoras que sólo pueden darse en el trópico. Argüello se hace partícipe de ese imaginario colonial, aunque al hacerlo denota un cierto tono burlón. Lo que es indiscutible es la presencia constante del referente europeo. De hecho, el narrador destaca la belleza de Costa Rica, que habría sido corroborada por "los extranjeros imparciales" que han visitado el país, de manera que "la fealdad es la excepción de la regla, principalmente en San José y entre las hijas de la clase acomodada" 8 . Cabe destacar que la belleza de las ticas es un tópico recurrente en la narrativa nacional.

La sobrevaloración que el autor hace de su patria sitúa a Costa Rica en un lugar privilegiado en el orden mundial; un paraíso que debe ser descubierto:

Lo que saco en limpio es que el mundo está por descubrirse aún y que conozco muchísimos lugares en Europa cuya descripción llena los diccionarios geográficos y las memorias de los turistas, que no resisten la comparación con este país y que están habitados por pueblos muy inferiores al de Costa Rica en cultura, civilización, riqueza y fuerza vital ${ }^{9}$.

8. Argüello, 217.

9. Argüello, 244. 
La excepcionalidad de Costa Rica es clara frente a sus vecinos centroamericanos, como queda demostrado por la calidad del sistema hotelero de San José, que ha sido elevado "a un grado desconocido en el resto de Centro América"10.

La novela se desarrolla en un paisaje netamente urbano y los protagonistas pertenecen a la clase acomodada, por lo que no podemos hablar de novela costumbrista. Sin embargo, es posible rescatar elementos destinados a crear en el lector un sentido de pertenencia a esa realidad que se pretende construir como propia y local. Para empezar, la red vial mencionada es netamente josefina, lo que tiene por efecto una identificación entre el paisaje interior de la novela y el paisaje exterior real. El lector no puede dejar de reconocer la calle del Comercio (actual avenida central), la calle de Chapuí (actual avenida sexta) y la calle del Seminario (actual avenida cuarta). En cuanto a los edificios públicos mencionados, se destacan el Palacio de Gobierno (cuyos bailes, según el narrador, están a la altura de aquellos efectuados en cualquier ciudad europea), la Municipalidad de San José, el Cuartel de Artillería (donde permanecen detenidos Julio Espinosa y Roberto Delgado), el Hospital de Locos de San José, la Iglesia de la Soledad, el Teatro Nuevo (Variedades) y el Hotel Francés. Fuera del ambiente urbano, nos encontramos con lugares como el volcán Irazú (donde puede realizarse el paseo "más agradable que puede hacerse en Costa Rica"), el territorio de los guatusos, Puntarenas, Orosi de Cartago, San Ramón, Hatillo y el Mojón (San Pedro de Montes de Oca). La referencia literaria a un paisaje por todos conocido es una manera de refundarlo y perpetuarlo en la memoria colectiva como el lugar geográfico habitado por la nación. En el caso de San José, este fenómeno cobra especial relevancia puesto que se reafirma su posición como capital del país.

10. Argüello, 282. 


\section{Contexto histórico y producción cafetalera}

Para muchos autores, el surgimiento de la novela en este período va unido al auge de la producción cafetalera, que le permitió a Costa Rica vincularse con el mundo en forma estable ${ }^{11}$. El cultivo del café fue de tal importancia para el país que llegó a modificar el entorno social: las tierras comunales fueron privatizadas, los pequeños productores se transformaron en jornaleros y la oligarquía liberal se apropió de la administración del cultivo por medio de la implementación de reformas destinadas a modernizar el país y estimular el capitalismo agrario.

El advenimiento de la actividad cafetalera reforzó la noción de sociedad agrícola que participa colectivamente en el proceso de producción ${ }^{12}$. Se privilegiaba un modelo patriarcal en el cual abundaban los pequeños propietarios, se difundió la imagen de la familia unida en torno a la tierra que retribuye al que la trabaja con perseverancia (visión, por lo demás, heredada de la era colonial). La nación costarricense es el producto final de un proceso de nacionalización, realizado por el Estado, en el cual intervinieron una serie de agentes intelectuales que "inventaron" la identidad nacional en la década de los ochenta del siglo xIX, y que terminó de consolidarse en $1949^{13}$. Antes de ello había un protonacionalismo que se limitaba a la idea de la integridad territorial y la soberanía. Los textos literarios sirvieron de soporte ideológicoen la elaboración de símbolos por su carácter interpelador, pero no debemos perder de vista que la narrativa privilegiaba la construcción de la nación de acuerdo con rasgos específicos que favorecían los intereses de la élite oligárquica.

El café es parte de la conciencia nacional costarricense, no sólo porque en el transcurso del siglo XIX se transformó en la principal

11. Iván Molina y Steven Palmer, Historia de Costa Rica (San José: Editorial de la Universidad dc: Costa Rica, 2002).

12. María Amoretti, "Sobre identidades y nacionalismos (contrastes metodológicos y epistemológi cos)" en Revista de Filología y Lingüística (Universidad de Costa Rica), XXV, 1 (1999).

13. Amoretti, op. cit. 
actividad económica del país, sino también porque dio origen a un imaginario que se ajustaba a los intereses de la oligarquía de aquel entonces: el pequeño propietario que trabaja la tierra en forma honesta, apoyado por el trabajo y el cariño de una familia unida. En Misterio, el esforzado cafetalero se hace presente a través de la figura de don Juan Escoto, quien consiguió comprar un terreno propio para café que en tres años tuvo limpio y sembrado, “...pero para eso fue preciso que el mismo padre, los niños y aun Narcisa tomaran la pala y el rastrillo, pues la esperanza era grande si se lograba llegar a la segunda cosecha o cuarto año"14 . La familia sigue unida también ante la adversidad, porque el trabajo perseverante es el camino al bienestar económico y a la armonía social. Se idealiza el núcleo familiar oligárquico-patriarcal como defensor de la estabilidad y la conservación de los valores tradicionales; esto provoca lo que Álvaro Quesa$\mathrm{da}^{15}$ denomina homologación entre familia oligárquica y nación, es decir, el dominio político-social ejercido por el padre sobre sus mujeres, su pueblo y su nación.

El café está presente en la vida cotidiana de los personajes; Delfina se aburre en el provinciano San José y añora la vida en París mientras contempla "las carretas llenas de sacos de café y tiradas por dos bueyes" "16. Rakosky menciona que en Londres se toma café de Costa Rica aunque los londinenses no saben a ciencia cierta donde queda el pequeño país que lo produce; Roberto y Julio saborean "el sabroso café a la crema" en uno de los recintos del Cuartel de Artillería; y al amanecer del día de la excursión al Irazú, los paseantes se sirvieron una taza de café. Al respecto, María Amoretti señala:

Así pues, el café se encuentra ligado a la concepción de la nacionalidad, no sólo en Costa Rica sino también en muchos otros países del área. En el nuestro es, además, símbolo nacional y la

14. Arguello, 226.

1.5. Álvaro Quesada, Breve historia de la literatura costarricense (San José: Editorial Porvenir, 2000).

16. Arguello, 217. 
literatura se ocupa de él precisamente en la época de consolidación del discurso nacional no sólo como simple escenario, sino además como metáfora de la evolución del país ${ }^{17}$.

Si bien la oligarquía dominaba en el interior de Costa Rica, el mercado internacional estaba dominado por las grandes metrópolis frente a las cuales el capital criollo se encontraba subordinado. Poresa razón, la elaboración del discurso nacional estuvo desde el principio impregnado de resistencia y contradicciones, sobre todo en lo relativo a la creación de una identidad diferente del modelo europeo, y la necesidad de desprenderse de ciertos valores tradicionales con el fin de insertarse en el mercado internacional. La oligarquía se sentía responsable de llevar adelante el proceso civilizador (educación y liberalismo) enfrentando los lastres heredados del pasado, como los privilegios, el dogmatismo eclesiástico, la ignorancia y las supersticiones populares. No es casualidad que la literatura en aquel tiempo la desarrollaran escritores que pertenecían a la élite aristocrática que tenía en sus manos el control del país, como es el caso de Manuel Argüello Mora.

Argüello se concentra en las intrigas amorosas, el tema del arribismo social, el honor, la traición, la sumisión femenina y la preservación del statu quo, siendo los protagonistas todos de la clase alta. Si aparece algún personaje de otro estrato social, lo hace en forma marginal y en función de los protagonistas ${ }^{18}$. En la novela Misterio se tiende a alabar las formas de vida europeas, las aspiraciones de los personajes son aristocratizantes y se hace énfasis en la conveniencia de la tutoría de la oligarquía sobre los demás sectores de la población. El final es feliz para la aristocracia y de resignación para los más pobres (recordemos que la fiel criada Narcisa debe "conformarse" con el cariño tranquilo que le profesa el sirviente africano Rakosky).

17. Amoretti, 16.

18. Quince Duncan, "Visión panorámica de la narrativa costarricense” en Revista Iberoamericana (138139) (Pittsburgh: Universidad de Pittsburgh, 1987). 


\section{Entorno social y personajes}

Los protagonistas de la novela pertenecen a la aristocracia costarricense o a la alta burguesía. Sus vidas transcurren con tranquilidad en una aldea nacional pacífica y con bastante estabilidad política. Los ojos de esa oligarquía están puestos en Europa como el modelo de la cultura y la civilización, por ello el estatus social de una familia se mide según la posibilidad que tenga de realizar viajes al viejo continente, o en su defecto, enviar allí a sus hijos para concluir los estudios. Esto confirma las características que ya hemos mencionado en relación con las aspiraciones aristocráticas y europeizantes de la clase oligárquica nacional. Recordemos que Delfina regresa de Europa a Costa Rica "vestida a la última moda, impregnada de la gracia parisiense y hablando muy bien el inglés y el francés" 19 ; también tenemos el caso de los matrimonios Espinosa y Rosales que "completaban su luna de miel con un viaje de placer a Francia e Italia" ${ }^{20}$. Por otra parte, la inmigración europea parece gozar de gran aceptación porque trae al país las innovaciones que ponen a Costa Rica a la altura del viejo mundo, como es el caso del empresario hotelero Gaetano de Benedictis.

La descripción de los personajes nos permite deducir los valores ideológicos del autor. Julio Espinosa posee todas las características necesarias para desempeñar un papel trascendente en la construcción nacional debido a su posición social, a su cuantiosa herencia y a su educación "perfecta". Es "el más arrogante joven de San José, simpático, valiente, liberal; era imposible tratarlo sin amarlo y admirarlo"21. La descripción física, que podría resultarnos pueril ("de talle más que mediano, moreno, bien formado y buen mozo indisputable"), no corresponde al actual imaginario que sostiene que el pueblo costarricense es de piel blanca. Lo mismo ocurre con Delfina, que, de acuerdo

19. Argüello, 214.

20. Argüello, 215.

21. Argüello, 216. 
con Rakosky, posee "ese color indescriptible que el sol de los trópicos imprime a los dichosos o desgraciados habitantes de esta zona"22.

Por otra parte, se vislumbra la presencia de una clase media emergente que, a punta de talento y trabajo, está destinada a integrarse a la clase oligárquica como una necesidad de renovar los "cuadros" de actores sociales. A modo de ejemplo, Roberto Delgado ("joven decente, bien educado y trabajador") no dispone de dinero o de una posición social que lo respalde, pero a través del matrimonio con la hija de un terrateniente venido a menos y a su perseverante esfuerzo, consigue enriquecerse "a la cabeza de una grande empresa de exportación de bananos". Delgado encarna el discurso de la modernidad y crecimiento de las relaciones mercantiles capitalistas desde el momento en que rompe con la tradición cafetalera para dar paso al cultivo del banano, lo cual significa la apertura a una nueva etapa en la historia nacional.

Pero no toda la clase media goza de la simpatía del narrador. El arribista funcionario público Andrés Cordón (es escribiente de un ministerio) se empeña infructuosamente en mostrar una alcurnia que en realidad no posee. Es el clásico caso del joven ambicioso que acude "a medios de dudosa moralidad para hacerse notable", puesto que no posee el talento ni la posición social. Andrés Cordón provoca intrigas más por estupidez que por maldad, sin embargo, al final de la novela se redime al rechazar un matrimonio por interés y dedicar su trabajo al bienestar de su madre y de sus hermanas.

\section{El discurso amoroso}

La retórica romántica es la que organiza la novela folletinesca. El lenguaje de amor, propio de la esfera doméstica, legitima a través del discurso amoroso el espacio público conformado por la nación. La creación de un modelo de familia paradigmático alude, por extensión,

$\overline{\text { 22. Argüello, } 245 \text {. }}$ 
a la formación de una familia-nación que es capaz de mantener la estabilidad incluso durante los períodos de conflictos extremos, como lo afirma Doris Sommer:

To paraphrase another foundational text, after the creation of new nations, the domestic romance is an exhortation to be fruitful and multiply. It will be evident that many of these romances strive toward socially convenient marriages and that, despite their variety, the ideal states they project are patriarchal or hierarchical ${ }^{23}$.

Los romances surgen entre héroes jóvenes, castos y hermosos, que establecen uniones conyugales que permiten las alianzas entre familias poderosas; esto no sólo significa unificar fortunas, sino que también constituye un símbolo de la unión nacional. La añorada estabilidad, propuesta como vía al progreso, se yergue sobre la base de la familia patriarcal; vale decir, se privilegia una distribución jerárquica de roles en el hogar de modoque el padre ejerce la autoridad y asume la responsabilidad del núcleo familiar en la esfera pública, mientras que la madre queda relegada al orden doméstico para cumplir sumisamente las funciones propias del "ángel del hogar". Siguiendo tradiciones ancestrales, la mujer es fuente de vida (la tierra), su más noble tarea es la de procrear hijos que continúen el legado de sus padres y perfeccionen el modelo de nación. El matrimonio es la institución destinada a mantener el orden patriarcal que le otorga al hombre el derecho de ser dueño de una mujer (ella sólo puede pertenecerle a él), pero lo erótico no tiene cabida en el discurso amoroso por propiciar el vicio y la decadencia moral.

Un elemento presente en la novela es el tema del incesto, que termina en locura. Doris Sommer señala el incesto como una suerte de "redundancia" de la ansiada unidad nacional. Los grupos aristocráticos,

23. Doris Sommer, "Irresistible Romance: The Foundational Fiction of Latin America" en Homi Bhabha (comp.), Nation and Narration (Londres: Routledge, 1990) 76. 
al tratar de mantener la pureza de casta que los distingue, tienden a caer en una excesiva endogamia que provoca la decadencia genética. Es posible que el fantasma del incesto sea la llamada de atención en cuanto a la necesidad de que la oligarquía acepte a individuos provenientes de otros sectores sociales.

\section{Relaciones de género y patriarcado}

El funcionamiento del orden social está ligado al acatamiento que los actores sociales hacen de su papel en el sistema jerárquico. De esta manera, la mujer acepta su papel de resguardadora del honor familiar por medio del control de sus apetitos sexuales y su respeto a la autoridad del padre o del esposo. Doña Inés se mantiene fiel al papel ritual de esposa virtuosa incluso meses después del fallecimiento de su marido; su mayor mérito es haber resistido la tentación de entregarse a una relación extramarital, a pesar del rechazo visceral que le provoca su marido. El recato y el decoro son virtudes propias de las damas costarricenses (doña Inés, Elena, Delfina); el desenfreno sexual viene de parte de las extranjeras. Recordemos que la relación que Andrés Cordón tiene con una actriz mexicana lo lleva al borde de la ruina, lo que nos hace pensar que el discurso nacional se apega a los valores morales tradicionales en contraposición al excesivo libertinaje que proviene del exterior.

Los hijos se someten a la autoridad del padre y los sirvientes obedecen las órdenes de sus patrones: Florencia carga con la culpa de haber cambiado la identidad de un recién nacido por el miedo de contrariar a su patrón, y Narcisa confunde sus propias aspiraciones con lasde la familia a la cual sirve, construyéndose así una relación de perfecta armonía entre los diferentes estratos sociales. Ninguno de estos actores rompe con el deber que les asigna el rito y la costumbre; de hecho, cualquier acto emancipador y autónomo podría conducir a un caos social no deseado. Estas normas se transforman en leyes no escritas que garantizan la moral y la estabilidad. 


\section{El Estado y los emblemas nacionales}

Si bien Misterio no pretende incursionar en el tema político, conviene destacar el episodio de Julio Espinosa y Roberto Delgado en el Cuartel de Artillería. El Estado cuenta con instituciones cuyas responsabilidades están claramente delimitadas, sólo que no ejercen su labor con la rectitud que debería esperarse. No es admisible que un rumor malicioso haya desencadenado un episodio de espionaje y arresto sin que haya existido la debida documentación probatoria. La disculpa personal del presidente no impide que Julio Espinosa pierda la confianza en el jefe de la nación, como si se diera inicio a un proceso de desconfianza de la misma oligarquía hacia las autoridades políticas; este aspecto me parece interesante porque la novela nació ligada al sistema burgués, pero su carácter polifónico le permite arremeter contra ese régimen burgués que, dicho sea de paso, está representado por la clase dominante a la cual pertenecía gran parte de los novelistas.

Es interesante destacar la alusión que en la novela se hace de los emblemas nacionales. Durante la velada realizada en casa de doña Inés, Rakosky le pide a Delfina que cante "alguna canción nacional o inspirada la música o la letra por un costarricense" 24 . El narrador posteriormente hace una completa reseña de la obra interpretada por la muchacha: "La letra de la canción fue compuesta en San Ramón en 1881, por el joven costarricense don David Hine y la música por el malogrado artista don Manuel Gutiérrez" ${ }^{25}$. En cierta forma, al mencionar a dos artistas el autor empieza a construir un canon con las figuras nacionales dedicadas al arte y a la cultura.

La conmemoración del 15 de septiembre merece ser señalada por la importancia que se le otorga en la novela. El acto comienza con el estampido de un cañón y culmina con un suntuoso baile realizado en el palacio de gobierno, aunque el narrador no deja de indicar que los festejos son relativamente austeros porque Costa Rica no es 24. Arguello, 237.

2.5. Argliello, 2.37. 
un país derrochador. Para los festejos existe un protocolo claramente definido: "A las nueve entró el presidente con sus ministros, y la orquesta ejecutó el himno nacional"26.

Otro aspecto que me parece importante tiene que ver con el uso del lenguaje, el cual representa un factor distintivo entre las nacionalidades. El narrador señala que doña Inés daba a su esposo el frío tratamiento de usted, mientras que su marido la trataba de vos. Como señala Argüello, el tuteo sólo se da en las relaciones muy íntimas, "y como nuestro objeto al escribir esta historia no es otro que dar a conocer nuestras peculiares costumbres y modos de ser usaremos de esa antigramatical manera de hablar"27.

Puesto que Misterio nació con el afán de convertirse en una novela educativa y no meramente de entretención, el autor pone de manifiesto su reproche a la ciudadanía por no recordar "nuestra pasada esclavitud, a pesar de que si algún pueblo de América ganó con la independencia, indudablemente fue Costa Rica; porque antes de gobernarnos nosotros mismos, éramos excesivamente pobres, casi miserables, y apenas paladeamos la autonomía, nos transformamos dejando atrás a Guatemala, El Ecuador, Bolivia y otras repúblicas a las cuales España dotó de grandes edificios para su culto y gobierno, con universidades y escuelas" 28 . Nuevamente observamos la convicción del autor de la excepcionalidad de Costa Rica.

Argüello Mora no recurre a documentos históricos para recrear épocas, se basa únicamente en su memoria y en su fantasía. Tal vez esa es parte de la debilidad en el texto que, como señala Álvaro Quesada, "ni en sus crónicas ni en sus relatos logra crear un sistema literario coherente y convincente, en que lenguaje, personajes y acontecimientos se organicen en una concepción original y perdurable de la realidad" ${ }^{\text {29 }}$. Puede que en ello influya el hecho de que se trate de una

26. Argüello, 262 .

27. Argüello, 235.

28. Argüello, 261.

29. Álvaro Quesada, La formación de la narrativa nacional costarricense (San José: Editorial de la Universidad de Costa Rica, 1986) 136. 
novela por entregas (el autor incluso equivoca el nombre de sus personajes). Sin embargo, se trata de una obra pionera de lo que sería la narrativa nacional costarricense.

Las narrativas nacionales centroamericanas fueron influenciadas por múltiples fuentes. El costumbrismo español tuvo especial relevancia, sobre todo los cuadros de costumbres de Mariano José de Larra. La poesía gauchesca se transformó en el ejemplo para América de lo "propio" cultural, y las Tradiciones peruanas de Ricardo Palma introdujeron en el texto literario documentos y hechos históricos (mezcla de verdad y fantasía) que servirían de inspiración a varios escritores centroamericanos.

\section{Conclusiones}

La consolidación de la independencia de las naciones americanas se llevó a cabo por medio de un lento y paulatino proceso de formación de identidades nacionales. Ante la heterogeneidad de las culturas que poblaban el continente, la clase político-oligárquica pronto comprendió la necesidad de crear un discurso nacional del cual todos se sintieran parte; sólo mediante un proceso de homogeneización ideológica era factible formar una conciencia identitaria, imprescindible para llevar adelante el proyecto hegemónico del liberalismo oligárquico.

La novela cumplió un importante papel en esta empresa en la medida en que refundó el paisaje nacional, re-escribió el pasado y creó un universo social (con sus creencias, sus mitos y sus costumbres) con el cual los lectores se sintieron identificados (dado el éxito que tuvieron las novelas analizadas). Si durante el siglo XIX se formó un sujeto cultural que habitaba en las fronteras del Estado independiente y autónomo, la novela ayudó a conformar un sujeto nacional con plena conciencia de sus rasgos distintivos frente a los sujetos de las naciones vecinas. En el caso de la novela centroamericana podemos notar que se da cabida a un universo regional, el lector siente que 
forma parte de un conglomerado más grande integrado por todos los países de la región.

Misterio es una novela fundadora de la narrativa nacional costarricense. Presenta un cuadro de costumbres de la época, critica los vicios sociales y apela a la complicidad del lector en cada denuncia, pero siempre en el entendido que la estabilidad se logra sólo a través del establecimiento de un sistema patriarcal muy jerarquizado, en el cual cada individuo conoce y acepta su lugar sin protestar. Si el sistema funciona, se da una buena amonía entre los representantes de los diferentes estratos sociales.

La literatura es una institución que selecciona lo que se quiere legitimar de la realidad, aparte de que exterioriza una visión moral y política del período relatado que resulta de gran utilidad para los grupos dominantes (los escritores del siglo XIX formaban parte de la clase hegemónica cuyo discurso se intentaba imponer). En el caso de Misterio, el narrador refuerza el sistema de valores producido por la oligarquía; no intenta desestructurar los mitos ni proponer una rebelión contra el orden establecido, sino simplemente perfeccionarlo. El discurso amoroso se consolida de manera paralela con la nación como ocurre con Julio Espinosa y doña Inés, pues los hijos que nacerán del matrimonio serán los constructores de la patria del futuro.

En general, las novelas latinoamericanas de fines del siglo XIX tienen más en común de lo que parece. Al margen de los defectos formales que podamos encontrarles, ellas representan una propuesta de realidad social acorde con el contexto de aquel tiempo. Hay un interés por limar asperezas y reconciliar diferencias, ya sean de clase, de raza o de partido. Esto no debe sorprendernos si consideramos que la élite blanca debía convencer a una población tan heterogénea, de su pertenencia a una nación única. Detrás de ello ciertamente subsistían intereses económicos, pero no debemos negar que el proyecto de una construcción identitaria dio sus frutos, los que se ven en la convicción de cada ciudadano de que es posible crear una Costa Rica más solidaria y más justa, es decir, la patria del futuro. 